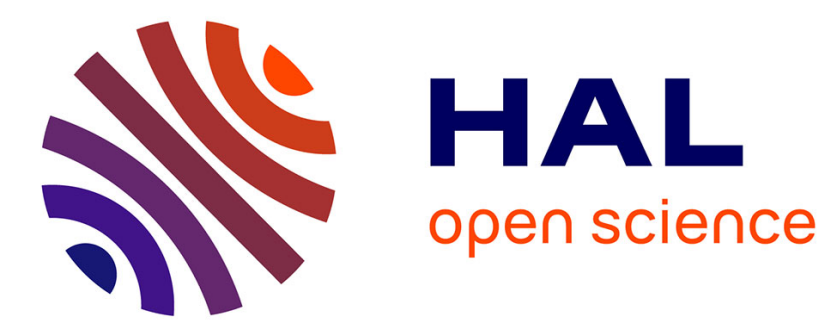

\title{
Assessment of velocity fields throught open-channel flows with an empiric law
}

J.B. Bardiaux, J. Vazquez, Robert Mosé

\section{To cite this version:}

J.B. Bardiaux, J. Vazquez, Robert Mosé. Assessment of velocity fields throught open-channel flows with an empiric law. Water Science and Technology, 2008, 57 (11), pp.1763-1768. 10.2166/wst.2008.290 . hal-00592189

\section{HAL Id: hal-00592189 \\ https://hal.science/hal-00592189}

Submitted on 24 Nov 2021

HAL is a multi-disciplinary open access archive for the deposit and dissemination of scientific research documents, whether they are published or not. The documents may come from teaching and research institutions in France or abroad, or from public or private research centers.
L'archive ouverte pluridisciplinaire HAL, est destinée au dépôt et à la diffusion de documents scientifiques de niveau recherche, publiés ou non, émanant des établissements d'enseignement et de recherche français ou étrangers, des laboratoires publics ou privés.

\section{다(1) $\$$}

Distributed under a Creative Commons Attribution - NonCommerciall 4.0 International 


\title{
Assessment of velocity fields through open-channel flows with an empiric law
}

\author{
J. B. Bardiaux, J. Vazquez and R. Mosé
}

Ecole Nationale du Génie de l'Eau et de l'Environnement de Strasbourg 1, quai Koch, B.P. 61039, 67070 Strasbourg cedex, France

\begin{abstract}
Most sewer managers are currently confronted with the evaluation of the water discharges, that flow through their networks or go to the discharge system, i.e. rivers in the majority of cases. In this context, the Urban Hydraulic Systems laboratory of the ENGEES is working on the relation between velocity fields and metrology assessment through a partnership with the Fluid and Solid Mechanics Institute of Strasbourg (IMFS). The responsibility is clearly to transform a velocity profile measurement, given by a Doppler sensor developed by the IMFS team, into a water discharge evaluation. The velocity distribution in a cross section of the flow in a channel has attracted the interests of many researchers over the years, due to its practical applications. In the case of free surface flows in narrow open channels the maximum velocity is below the free surface. This phenomenon, usually called "dip-phenomenon", amongst other things, raises the problem of the area explored in the section of measurements. The work presented here tries to create a simple relation making possible to associate the flow with the velocity distribution. This step allows to insert the sensor position into the flow calculation
\end{abstract}

Key words | empiric law, open-channels flow, sewer networks, velocity fields

\section{INTRODUCTION}

The lawful constraints on the sewer networks were developed since about fifteen years now. Indeed the January 1992 national water policy law transposed from the May 1991 European Community Directive stipulates that any town, producing a daily pollutant load of more than $900 \mathrm{~kg}$, has to be equipped with a wastewater collection network. Moreover, according to the decree of the 22nd December, relating to the self survey, in order to better evaluate the depollution rate of a system, it is necessary to install measuring equipment able to estimate the flows moving towards the plants or the discharge system. Besides the fact that the usual hypothesis about spatial homogeneity for flow rates and pollutant loads is false (Wohrle \& Brombach I99I), the dual behavior of some wastewater collection networks, combined sewer system for example, make difficult the flow rates measurements. A better assessment of the spatial distribution of the doi: $10.2166 /$ wst.2008.290 velocities in a cross section is, therefore, one way to improve the flow assessment. The present paper presents an empirical law intended to calculate, for a fully developed flow in a given cross section, the spatial distribution of the velocity in relation to channel shape and water level. Then a velocity profile measured by a Doppler sensor, combined with this law, gives a way to estimate mean velocity and also water discharge. Moreover, this approach permits to take into account the sensor position and the water level variation during wet event.

\section{METHODS}

The followed method is aims to create a simple law allowing determining, in any point of a section, the local velocity of a flow. This relation has to be simple, because it will be 
Table 1 | Fluent simulation framework

\begin{tabular}{|c|c|c|c|}
\hline Shape & Rectangular & Circular & Egg-shape \\
\hline Dimensions (mm) & $\begin{array}{l}\text { Width } \times \text { height: } 600 \times 800 ; 1,000 \\
\quad \times 500 ; 2,000 \times 500\end{array}$ & Diameter: $500 ; 1,000 ; 1,500 ; 2,000$ & Height: 1,$000 ; 1,500 ; 2,000$ \\
\hline Filling $(\%)$ & $20 ; 30 ; 40 ; 50 ; 70 ; 90$ & $20 ; 30 ; 40 ; 50 ; 70 ; 80$ & \\
\hline Mean Velocity (m/s) & $0.25 ; 0.5 ; 0.75 ; 1.00 ; 1.25 ; 1.5 ; 2$ & & \\
\hline
\end{tabular}

inserted in the sensor measurements line. Simple models already exist (Nezu \& Rody I986) and (Czernuszenko \& Rylov 2000, 2002), but, although they are defined on the whole section and they can not simulate the dip-phenomenon. The objective of this study is clearly to develop a tool taking into account so much the space variability of the velocity field as the sensor position. The challenge is clearly here to know this field only from the hydraulic characteristics, i.e. the geometry channel and the water level. Methodology reveals three stages

\section{First stage: numerical modeling}

The method starts with the numerical simulations of different flows in several classical sections (in sewer networks): rectangular, circular and egg-shape. Table 1 shows the list of all the simulations realized with the Fluent software.

It begins with the definition of the modelling way. The main problem with the open channels remains the free surface and the anisotropy of the turbulence. The many studies realised (Larrarte et al. 2005) showed that the best way to have a good agreement with the reality (Bonakdari et al. 2007) were the V.O.F method (Volume Of Fluid: diphasic model) combined with the anisotropic R.S.M. model (Reynolds Stress Model) for the turbulence (Bardiaux et al. 2006).

\section{Second stage: a velocity field for each kind of channel}

The library of velocity fields obtained, for each kind of channel and each filling value, allows us to generate a representative field, called medium field. After having transformed the fields within a dimensionless channel (the position is now given by $\xi=Z / h_{\text {water }}$ and the relative distance from the wall $y / B$ ), each local velocity of the medium field is divided by the associated mean velocity. Finally, an average element is calculated with all those local ratio.

\section{Last stage: fit an algebraic formulation to the medium field}

The formulation chosen here is obviously based on the known description of classical velocity fields in openchannels (Nezu \& Nakagawa 1993). Thus, logarithmic law (for the "vertical" behavior) and power law (for the horizontal one) have been crossed. Moreover, in the aim of taking into account the dip-phenomenon, a trigonometric one has been added. Finally, to limit the asymmetric effects, we use absolute value. Then, the formulation proposed is the following one (Equation (1)):

$\frac{U}{U_{\text {mean }}}=\left[|a \cdot \ln (\xi)+b+c \cdot \sin (d \cdot \xi)|+e \cdot\left(\frac{y}{B}\right)^{f}\right] \cdot\left(\frac{y}{B}\right)^{g}$

where $a, b, c, d, e, f, g$ are empiric parameters stemmed to the fitting, depending on the water level.

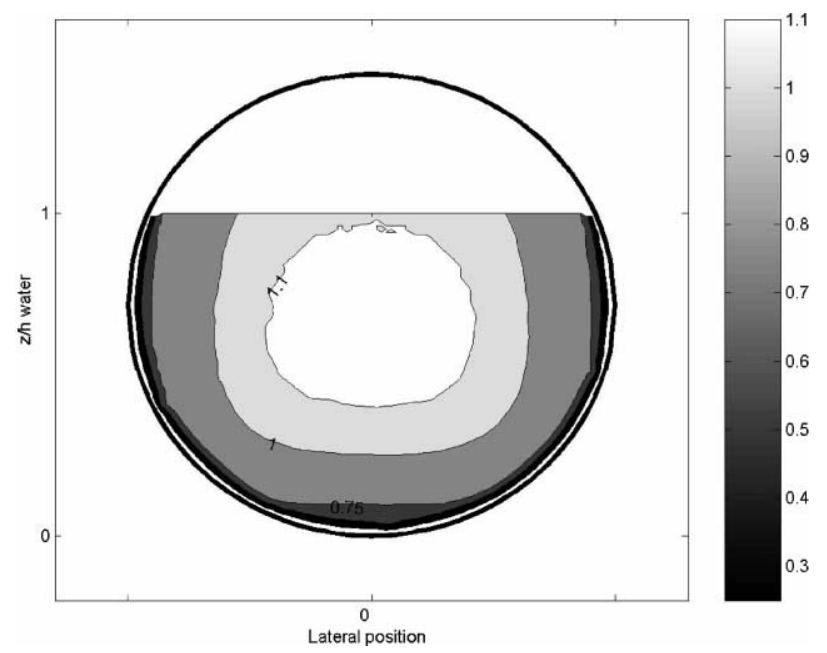

Figure 1 Isolevels of $U / U_{\text {mean }}$ for circular pipe with $h / D=0.7$. 


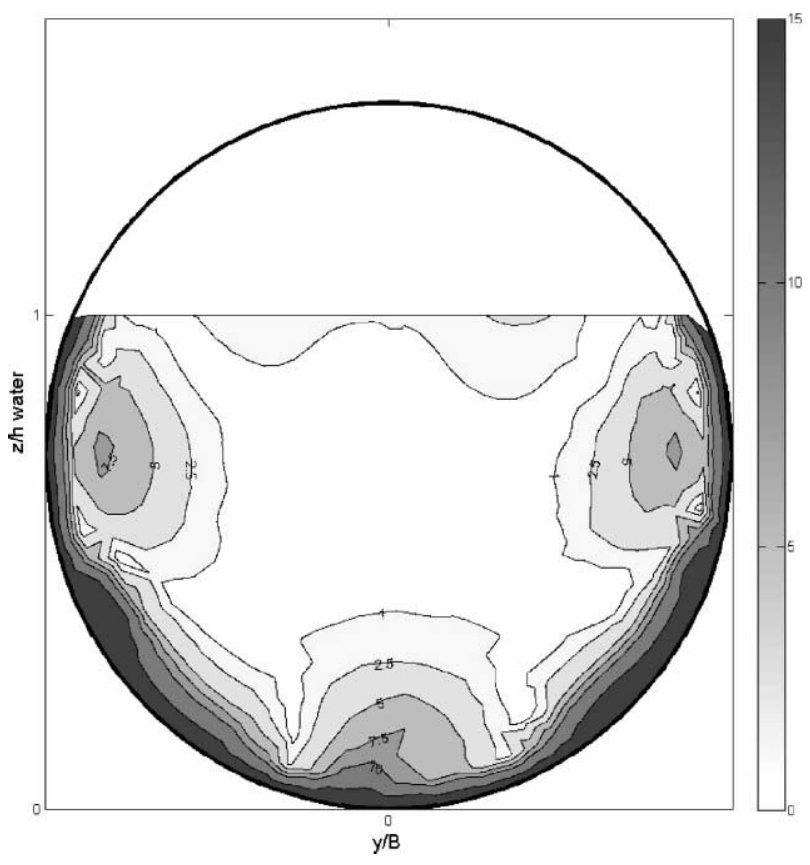

Figure 2 | Error (\%) between numerical simulations and Equation (1).

Figure 1 shows, for example, the $U / U_{\text {mean }}$ distribution for circular pipes obtained by the application of the Equation (1), for one filling, 70\%. The particular behavior of the maximal velocity appears clearly.

Figure 2 gives the comparison between the dimensionless medium field stemming from Fluent output data and the dimensionless field stemming from the Equation 1 application. It shows that the error is around 15\% near the wall. But the target is the use of such model with a Doppler sensor giving velocity profiles. As, on the one hand, a transductor keeps an invalid measurements zone up to more or less $15 \mathrm{~cm}$ (depending on the frequency) and, on the other hand, the submerged part of the measuring device

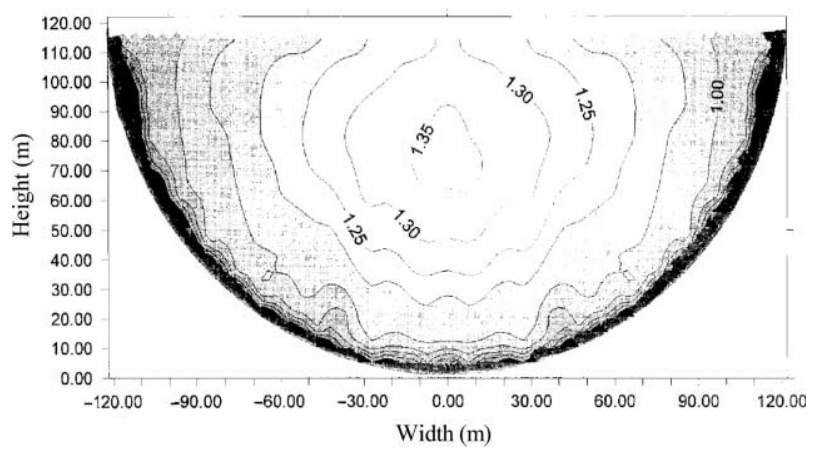

Figure 3 | Isolevels of $U / U_{\text {mean }}$ in a circular pipe (Knight \& Sterling 2000).

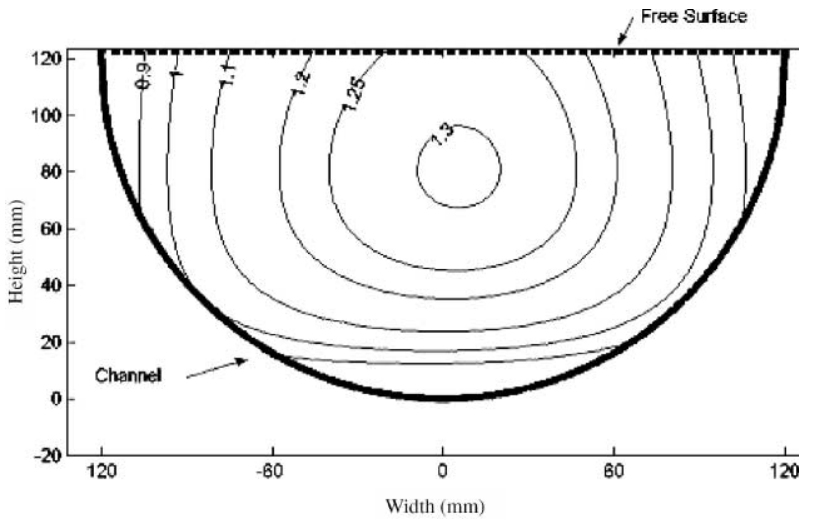

Figure 4 | Isolevels of $U / U_{\text {mean }}$ from equation (1).

is around $7 \mathrm{~cm}$, the unavailable area reaches more or less $20 \mathrm{~cm}$. So the information lost is not harmful for the flow rates assessment.

Now, according to the shape, water height and the velocity profile measured, the mathematical treatment on line must reveal the different mean velocity value, for each localization. But, before, let us validate the model based on Equation 1.

\section{RESULTS}

\section{Circular open-channel}

\section{Description of the data}

The data presented in Figure 3 correspond to a flow through a circular pipe $(Q=11.7 \mathrm{l} / \mathrm{s}$ and diameter $=123 \mathrm{~mm}$, water level $=123.5 \mathrm{~mm})$ (Knight \& Sterling 2000).

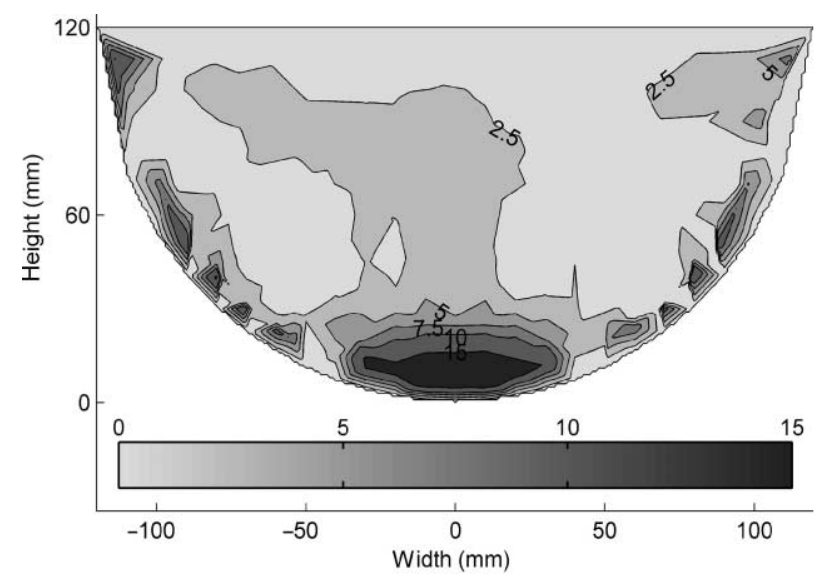

Figure 5 | Spatial distribution of the error (\%). 


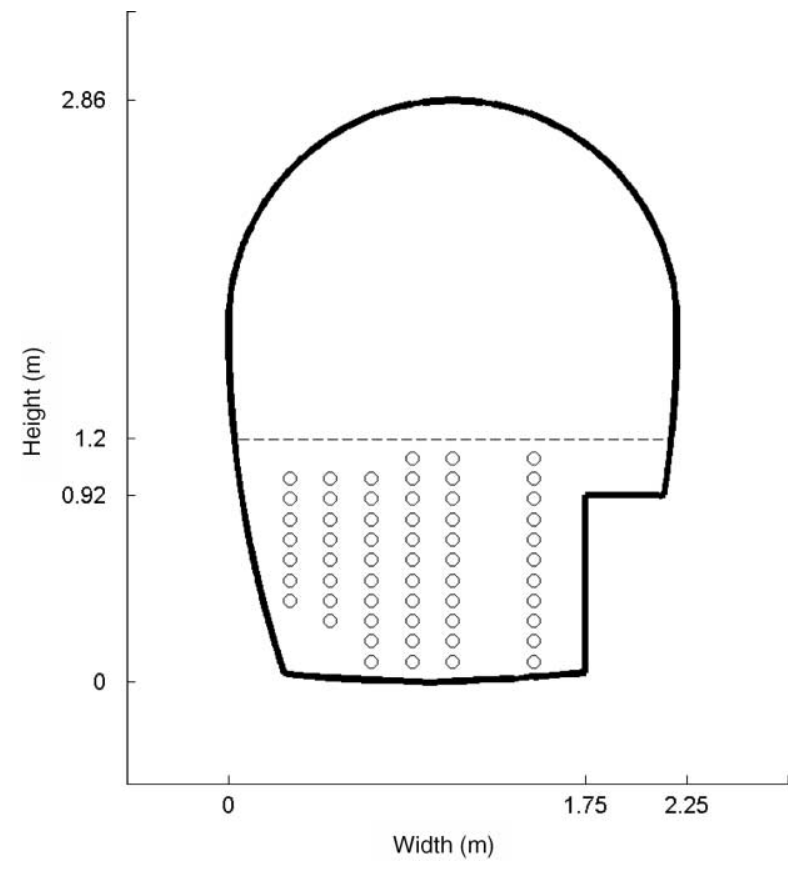

Figure 6 | Measurements point (0) on Cordon Bleu site (from Larrarte 2006).

\section{Application of Equation (1)}

Figure 4 shows the ability of Equation (1) to simulate the velocity field on around 80\% (less than 5\%) of the section with a good agreement, but around the wall the model is inadequate. The right position of the dip-phenomenon is clearly in Figure 4, despite a weaker maximal velocity.

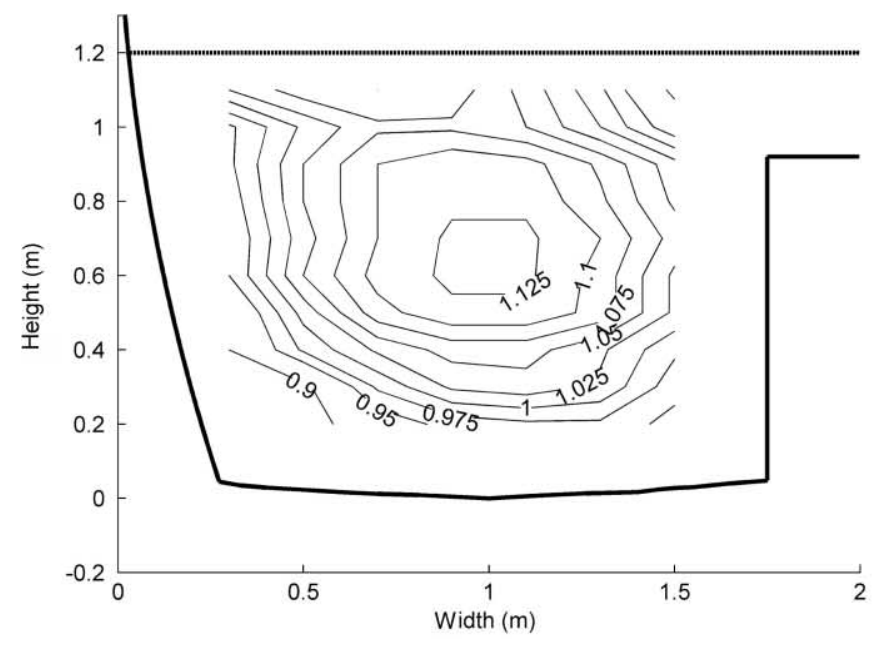

Figure 7 | Isolevels of velocities in Cordon-Bleu a) measurements and b) model.
According to Figure 5, this approach presents a good agreement with the experimental data. In fact, unlike Coles relation, this model is able to simulate the dip-phenomenon on the right position.

\section{Experimental site in a sewer network}

The experimental site (Figure 6) is located in an area called Cordon Bleu, a few kilometres upstream the treatment plant on the main sewer line of the city of Nantes (west of France). In the egg-shape pipe, the mean velocity was $0.88 \mathrm{~m} / \mathrm{s}$, whereas the water height was $1.20 \mathrm{~m}$, as shown in Figure 6. No measurements could be realised over the walkway but a wide range of flow conditions have been experimentally investigated (Larrarte 2006).

Figure 7 raises, like Figure 4, a good description in the central region, less than 5\%. But, the walk-away generates special flows (re-circulations), which are not correctly reproduced. Figure 8 includes the profiles mentioned on Figure 6. All seems to present a good agreement except the last $(1.5 \mathrm{~m}$ from the wall) around the walkway. Obviously, the asymmetric shape disagrees with the symmetric equation. More measurements are planned to test the impact on the water discharge assessment.

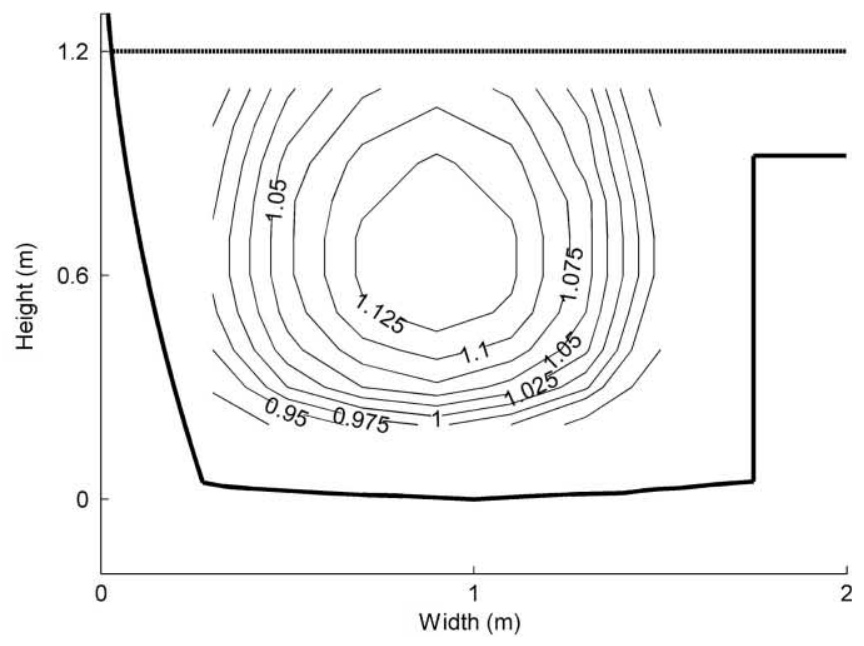



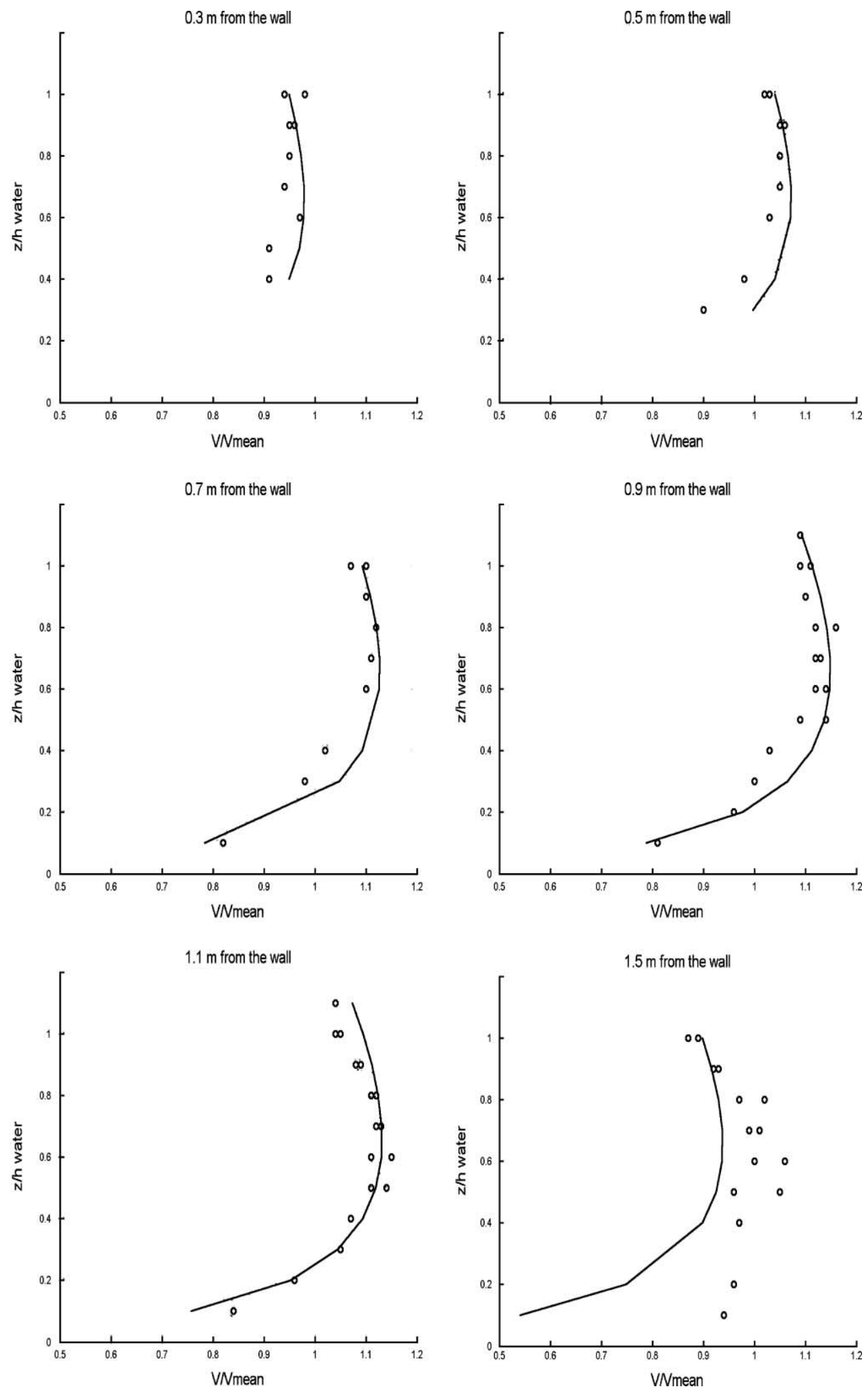

Figure 8 Different profiles (0) measured, (-) from Equation1 in Cordon Bleu. 


\section{CONCLUSION}

The model presented here allows a good representation of a velocity field in a fully developed flow. The advantage is to be independent of the measurements conditions. Indeed, geometry and water level are sufficient to reach an assessment of the flow rate. Thus, if a sensor gives a partial chord (range limit), it is possible to build up the whole field and estimate the flow rate. Furthermore, if the sensor has to be fastened on sideways, the localisation of the sampled volume can be used even if the maximal velocity area is not scanned.

Certainly the nearness of the walls remains a problem but this is not the area, which contributes the most to the flow rate and it corresponds often to a invalidate sensor zone. But the main work to add is the treatment of the walk-away area. Indeed, local deformation of the velocity field cannot be simulated with the expression (1). Data acquisition on a new physical model $(20 \mathrm{~m} \log , 1 \mathrm{~m}$ high and $0.6 \mathrm{~m}$ wide) will help us to improve this.

Finally, the approach developed in this paper aims to improve Doppler use, introducing few hydraulic rules.

\section{REFERENCES}

Bardiaux, J. B., Bonakdari, H., Larrarte, F., Mose, R. \& Vazquez, J. 2006 Velocity profiles through a sewer channel using CFD to obtain velocity fields. Strömungssimulation in Wasserbau, Dresdner Wasserbaukolloquium, 9-10 March 2006.

Bonakdari, H., Larrarte, F. \& Bardiaux, J. B. 2007 Experimental and computational study of velocity fields in narrow or compound section sewers. Water Practice Technol. 2(2), online only (doi 10.2166/wpt.2007.040).

Czernuszenko, W. \& Rylov, A. 2000 A generation of Prandtl's model for 3D open channel flow. J. Hydraulic Res. 38(2), 133-139.

Czernuszenko, W. \& Rylov, A. 2002 Modeling the three dimensional velocity field in open channel flows. J. Hydraulic Res. 40(2), 135-143.

Knight, D. W. \& Sterling, M. 2000 Boundary shear in circular pipes running partially full. J. Hydraulic Eng. 126(4), 263-275.

Larrarte, F. 2006 Velocity fields in sewers: an experimental study. Flow Meas. Instrum. 17(5), 282-290.

Larrarte, F., Bardiaux, J. B. \& Bonakdari, H. 2005 Computational and experimental study of velocity profiles in sewers. 10th International Conference on Urban Drainage. Copenhagen, Denmark, 21-26 August 2007.

Nezu, I. \& Nakagawa, H. 1993 Turbulence in Open-channel Flows, IAHR, 281p.

Nezu, I. \& Rody, W. I986 Open channel flow measurements with a Laser Doppler anemometer. J. Hydraulic Eng. 112(5), 335-355.

Wohrle, C. \& Brombach, H. I99I Probenahme im Abwasserkanal. Wasserwirtschaft 81, 60-65. 